\title{
Embryogenesis of Aphidoletes aphidimyza (Diptera: Cecidomyiidae): Morphological markers for staging of living embryos
}

\author{
JAN HAVELKA ${ }^{1}$, VladimÍR LANDA JR. ${ }^{2}$ and VLADIMÍR LANDA ${ }^{1}$ \\ ${ }^{1}$ Institute of Entomology, Academy of Sciences of the Czech Republic, Branišovská 31, 37005 České Budějovice, Czech Republic; \\ e-mail: jhav@entu.cas.cz \\ ${ }^{2}$ Institute of Experimental Medicine, Academy of Sciences of the Czech Republic, Vídeňská 1083/270, 14220 Praha 4 - Krč, \\ Czech Republic
}

Key words. Cecidomyiidae, Aphidoletes aphidimyza, biological control, aphids, insect embryogenesis, embryonic markers, cryopreservation of eggs, entomophagous insects

\begin{abstract}
Determination of embryonic stages is an important prerequisite for the long-term cryopreservation of eggs and embryos of the predatory gall midge Aphidoletes aphidimyza. This paper describes the embryonic development of this insect based on light microscopy. Gall midge embryogenesis lasts, on average, $102 \mathrm{~h}$ at $17^{\circ} \mathrm{C}$ and $144 \mathrm{~h}$ at $15^{\circ} \mathrm{C}$. Living embryos can be quickly separated into ten stages that are clearly defined by specific morphological markers. The necessity for selecting definite embryonic stages for cryobiological storage is discussed.
\end{abstract}

\section{INTRODUCTION}

The predatory gall midge Aphidoletes aphidimyza (Rondani) (Diptera: Cecidomyiidae) is an effective biological control agent that has been used for the biological control of aphids in greenhouse crops (Asyakin, 1974; Markkula et al., 1977; Havelka, 1982; Kulp et al., 1989) since 1973.

Long periods of storage of insects at low temperatures is an important component of mass laboratory rearing and crucial for establishing population banks of selected species.

Diapausing larvae in cocoons are used in biological control practice.

Storage at $3{ }^{\circ} \mathrm{C}$ under continuous darkness extends shelf life of stored insects for up to 7 month, with survival rates above $50 \%$. Diapause of most specimens is terminated within 120 days of chilling (Koštál \& Havelka, 2001). The exposure to low positive temperatures ensures cold reactivation (Havelka, 1996).

The discovery of great variability in many bionomical characteristics among the geographic populations of $A$. aphidimyza (Havelka \& Zemek, 1988, 1999) revealed that the efficiency of this biological control agent can be improved by selection of suitable parameters (e.g. high fecundity, short oviposition period, non-diapausing type of development, preference for low relative air humidity). Such improvements based on selection and hybridization need the simultaneous maintenance of multiple breeding populations. It is costly and can lead to changes in population characteristics due to long term laboratory rearing. The cryopreservation of gall midge embryos can solve this problem.

Cryopreservation of insects in liquid nitrogen has been achieved over the last ten years using embryos at welldefined developmental stages. The main groups of dip- terous insects studied in detail are as follows: Drosophilidae - Drosophila melanogaster (Myers et al., 1988; Leopold, 1991; Mazur \& Cole, 1992; Mazur et al., 1992, 1993), Muscidae - Musca domestica (Heacox et al., 1985; Wang et al., 2000), Tephritidae - Ceratitis capitata, Anastrepha suspensa, A. ludens (Rajamohan et al., 2003), Calliphoridae - Lucilia cuprina and Cochliomyia hominivorax (Leopold \& Atkinson, 1999; Leopold et al., 2001), Culicidae - Anopheles gambiae, A. quadrimaculatus (Valencia et al., 1996a, b; Liu et al., 2001, 2003; Liu \& Mazur, 2003) and Ceratopogonidae - Culicoides sonorensis (Nunamaker \& Lockwood, 2001).

Development of a cryopreservation method includes five steps:

1. Staging of embryos using characteristic markers; 2. Selection of the most appropriate developmental stage for cryopreservation; 3 . Selection of cooling rate to $-205^{\circ} \mathrm{C}$ (liquid nitrogen) after permeabilizing and loading embryos with hypertonic ethylene glycol; 4. Selection of a warming rate for revival; 5. Finding the conditions optimal for the completion of embryonic development (hatching of larvae). The purpose of this study is to determine the embryonic stages of $A$. aphidimyza reared under constant laboratory conditions and identify stage-specific markers that can be used in the cryopreservation of this species (i.e. the $1^{\text {st }}$ and $2^{\text {nd }}$ steps).

\section{MATERIAL AND METHODS}

\section{Egg collection and staging}

The laboratory population was established from larvae collected in a colony of the aphid Impatientinum asiaticum Nevsky on Impatiens parviflora (L.) at České Budějovice, Southern Bohemia $\left(49^{\circ} \mathrm{N}, 14^{\circ} \mathrm{E}\right)$ in August 1997. The aphidophagous gall midges were reared at $17 \pm 1.0^{\circ} \mathrm{C}$ and a photoperiod of $18 \mathrm{~L}$ : $6 \mathrm{D}$. This constant temperature is at the lower limit of this species optimum zone (mortality near zero) and results in slow 
TABLE 1. Embryonic development of Aphidoletes aphidimyza.

Stages of embryonic development of Drosophila

melanogaster (Wieshaus \& Nusslein-Volhard, 1986)

\begin{tabular}{cl} 
No. & Some characteristic processes and features \\
\hline 1 & Cleavage process; egg cytoplasm is homogenous \\
2 & Cleavage process; clear cap of posterior polar cytoplasm \\
& (retraction of cytoplasm from vitelline membrane at poles)
\end{tabular}

3 Cleavage process; pole cell nuclei form buds at posterior end

4 Cleavage process; pole cell nuclei cellularize to form pole cells over blastoderm nuclei (syncytial blastoderm), peripheral migration of nuclei

5 Cellularization of blastoderm; pole cell migration begins

6 Early gastrulation; invagination of mesoderm and endoderm primordia, dorsal plate forms; cephalic and ventral furrows form

7 Gastrulation complete; invagination of anterior and posterior midgut; formation of dorsal folds

8 Amnioproctodeal invagination elongation of germ band mesoderm segmented

9 Stomodeal plate formation; dorsal folds and cephalic furrow disappear

10 Maximum elongation of germ band stomodeal invagination

11 Parasegmental furrows appear, germ band shortening begins at end of stage

12 Germ band shortens; clear segmentation

13 End of germ band shortening; head involution begins

14 Head involution; midgut and dorsal closure

15 Completion of dorsal closure; anal plates and posterior spiracles distinct

16 Intersegmental grooves clear in mid-dorsal region; dorsal ridge overgrows tip of clypeolabrum

17 Muscular movements; air in tracheae; condensation of central nervous system

18 Hatching of larva
Stages according to simplified scheme of embryonic development of Aphidoletes aphidimyza

No. Characteristic markers

1 Egg cytoplasm is homogenous

2 Cleavage process; clear cap of posterior polar cytoplasm (retraction of cytoplasm from vitelline membrane at poles)

2 Cleavage process; buds at posterior end of egg

2 Cleavage process; buds at posterior end of egg

3 Cellularization of blastoderm

4 Early gastrulation

4 Invagination of anterior and posterior midgut; formation of dorsal folds

4 Amnioproctodeal invagination elongation of germ band, mesoderm segmented (parasegmental furrows)

4 Stomodeal plate formation

4 Maximum elongation of germ band; stomodeal invagination; clear segmentation

5 Germ band shortens

5 Germ band shortens; clear segmentation

6 End of germ band shortening; the clypeo-labrum is distinct

7 Head range involution; midgut and dorsal closure begins

8 Completion of dorsal closure; anal plates and posterior spiracles distinct

8 Intersegmental grooves clear in mid-dorsal region; dorsal ridge overgrows tip of clypeolabrum

9 Muscular movements

10 Hatching of larva development (Havelka, 1980). Newly emerged adults of $A$. aphidimyza were placed in $1250 \mathrm{ml}$ plastic container. Adults were fed by placing tissue paper soaked in 5\% saccharose solution under the lid. Individual cultures contained about 400 gallmidges of both sexes. Ventilation was ensured by two nylon-covered holes on the sides of the bottomless container, which rested on a perforated lid of a plastic cup filled with water. A bean seedling (Vicia faba L.), about $3 \mathrm{~cm}$ long, infested with Aphis fabae Scop. (approx. 40 aphids per plant), was placed into a hole in the lid to stimulate the gall midges to oviposit. Eggs were collected at night after $8 \mathrm{~h}$ exposure to the aphid stimulus (from 22 p.m. till 6 a.m.). Gall midges (minimum 200 females) laid eggs in the bean-aphid colony. The plants with eggs were transferred into plastic cups covered with a layer of tissue paper and nylon netting. Larvae were fed on the pea aphid Acyrthosiphon pisum (Harris). High relative air humidity was maintained in the rearing cups by the pieces of plant, or by fixing a wall of wet cotton wool to the upper part of the cup. Prior to pupation, mature larvae produced cocoons in a $2-3 \mathrm{~cm}$ layer of fine, cleaned quartz sand, sterilized with boiling water. The cocoons of $A$. aphidimyza were passed through a set of sieves, cleaned of organic debris and placed in incubators with a constant humidity close to $100 \%$ (Havelka \& Zemek, 1988).

The eggs for experiments were collected from the plant surface using a very fine needle and were immediately transferred for $2 \mathrm{~min}$ into a drop of $2.5 \%$ sodium hypochlorite, or $50 \%$ solution of commercial bleach solution SAVO (with $5 \%$ of sodium hypochlorite) to remove the chorion. The treatment time was selected after preliminary experiments to determine the treatment that gave the best egg survival.

\section{Microscopy of living embryos}

The whole embryonic development was observed and photographed using living eggs submerged in various media under a dissecting microscope, using transmitted light (column a in the figures - dorsoventral view, column $\mathrm{b}$ - lateral view, and column $\mathrm{c}$ - phase contrast microphotograph with descriptions of markers). A collection of washed eggs was placed on a plate or small Petri dish. Terasaki plates proved very suitable. The solution used for the cultivation of mammalian embryos, PBS (phosphate buffer solution) was used for the embryonic development studies. Transfer and manipulation of embryos were done with 
TABLE 2. Rate of embryonic development of Aphidoletes aphidimyza at constant temperatures.

\begin{tabular}{cccl}
\hline Stage & $\begin{array}{c}\text { Approximate age } \\
\text { of egg (h) at } 15 \pm 1.0^{\circ} \mathrm{C}\end{array}$ & $\begin{array}{c}\text { Approximate age } \\
\text { of egg (h) at } 17 \pm 1.0^{\circ} \mathrm{C}\end{array}$ & Pivotal markers observable using transmitted light microscopy \\
\hline 1 & $1-3$ & $1-2$ & Egg cytoplasm is homogenous \\
2 & $3-9$ & $2-6$ & Pole buds at posterior end of egg \\
3 & $9-21$ & $6-12$ & Cellularization of blastoderm \\
4 & $21-57$ & $12-33$ & Elongation of germ band; stomodeal invagination; clear parasegmentation \\
5 & $57-66$ & $33-48$ & Germ band shortens \\
6 & $66-75$ & $48-60$ & End of germ band shortening \\
7 & $75-90$ & $60-72$ & Head involution \\
8 & $90-117$ & $72-84$ & Dorsal ridge overgrows tip of clypeolabrum; midgut and dorsal closure \\
9 & $117-144$ & $84-102$ & Muscular movements; white "vacuole" in the hind gut region \\
10 & $>144$ & $>102$ & Hatching of larva \\
\hline
\end{tabular}

the aid of a capillary glass tube. This method, which is suitable for handling large numbers of embryos, is described in more detail in another paper (Landa et al., in prep.). Zeiss Amplival optics (Zeiss Semiplan 10× objective) and an Olympus BX41 microscope (Olympus Plan N 10× objective) with phase contrast and an Olympus DP 10 camera were used for digital image documentation. Structures in living eggs were compared with those in other Dipteran species - particularly Drosophila (Poulson, 1950; Sonnenblick, 1950; Van der Starre-Van der Molen, 1972; Wieshaus \& Nüsslein-Volhard, 1986; Ashburner, 1989).

\section{RESULTS}

\section{Progress of embryonic development}

The shape of a newly laid fertilized egg is elongateellipsoidal and is bright orange, ca. $0.23 \mathrm{~mm}$ long and 0.05 wide. The chorion $(\mathrm{CH})$ is smooth, colourless, translucent and very thin.

The duration of embryonic development from oviposition to hatching depends on temperature (Havelka, 1980). For the geographical population investigated it lasts about

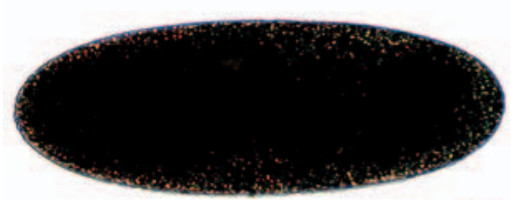

$1 \mathrm{a}$

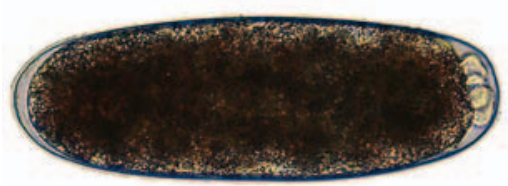

$2 a$

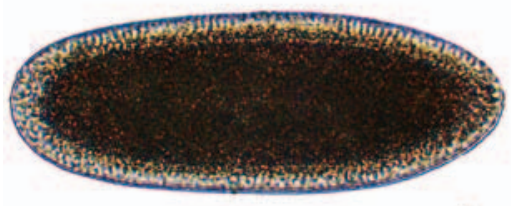

3a

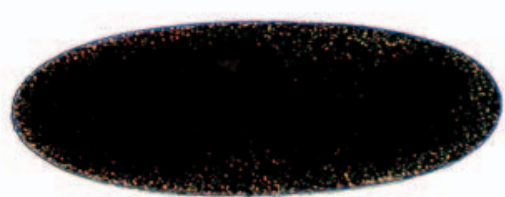

$1 \mathrm{~b}$

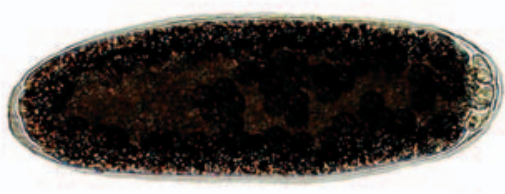

$2 b$

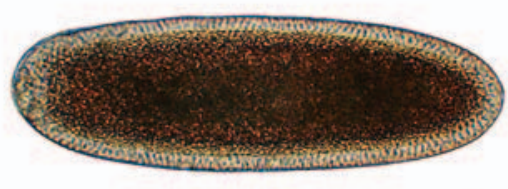

$3 \mathrm{~b}$
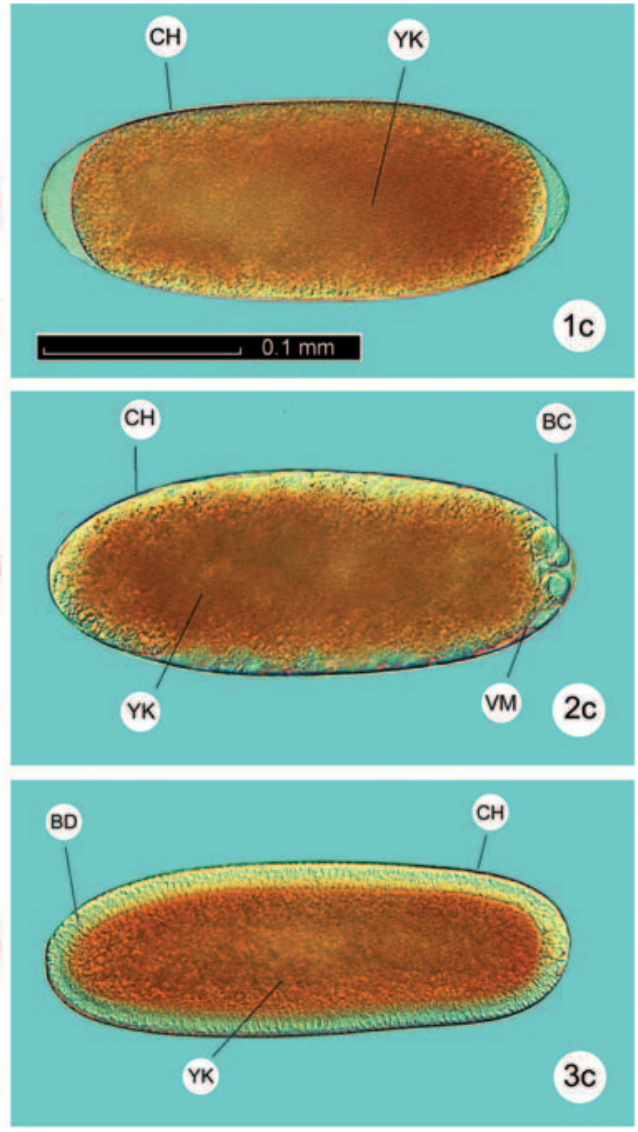

Figs 1-3. Stage 1: Cleavage process; egg cytoplasm is homogenous. $\mathrm{CH}$ - chorion; YK - yolk. a - dorsoventral view; $b$ - lateral view; c - phase-contrast. Stage 2: Cleavage process; syncytial embryo with three pole buds; clear cap of posterior polar cytoplasm. $\mathrm{CH}$ - chorion; YK - yolk; VM - vitelline membrane; $\mathrm{BC}$ - posterior pole buds. Stage 3: Cellularization of blastoderm. BD - blastoderm; $\mathrm{CH}$ - chorion; YK - yolk. 


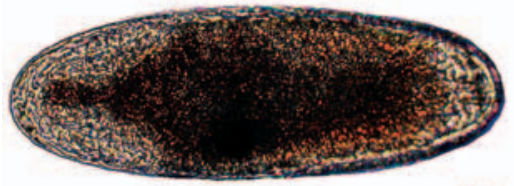

$4 a$

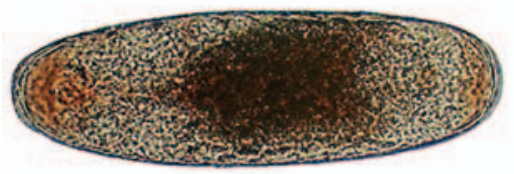

5

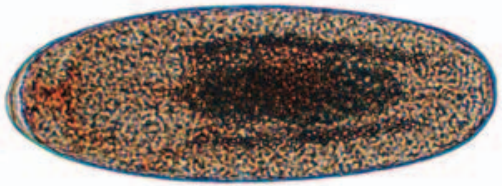

$6 a$

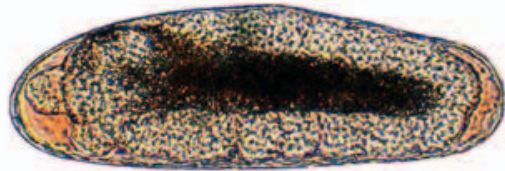

$4 b$

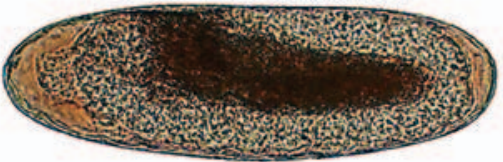

$5 b$

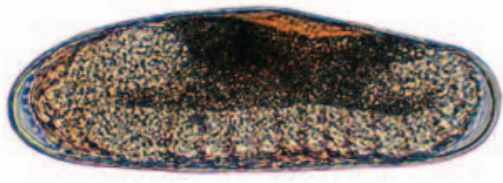

$6 b$
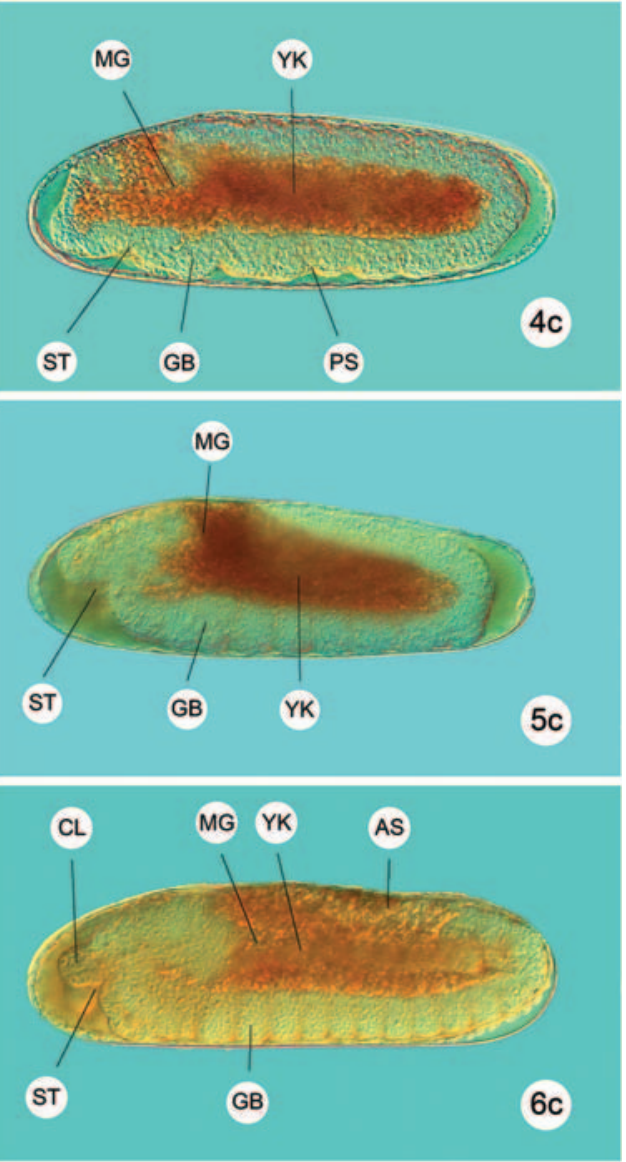

Figs 4-6. Stage 4: Gastrulation: stomodeal invagination, dorsal folds form; elongation of germ band; clear parasegmentation. GB - germ band; SP - stomodeal plate; MG - midgut; YK - yolk; PS - parasegments. Stage 5: Germ band shortens. GB - germ band; ST - stomodeum; MG - midgut; YK - yolk. Stage 6: End of germ band shortening; head involution begins. GB - germ band; ST stomodeum; CL - clypeo-labrum; MG - midgut; YK - yolk; AS - amnio-serosa.

$102 \mathrm{~h}$ (about 4 days) at $17 \pm 1.0^{\circ} \mathrm{C}$ and about $144 \mathrm{~h}$ at 15 $\pm 1.0^{\circ} \mathrm{C}$. This period can be divided into ten stages, on the basis of changes in microscopic embryonic features. The most convenient markers are summarized in Table 1 and the progress through these stages is shown in Table 2. Dorsoventral and lateral planes of the embryos (Figs 1-10) are shown in longitudinal section. Stage 1-3 are pregastrula stages. Embryonic features - markers are very similar to those in other dipterous species.

Stage $1\left(1-3 \mathrm{~h}\right.$ at $\left.15^{\circ} \mathrm{C}\right)$ : The yolk (YK) is a homogenous granular mass but in some eggs clear caps of polar cytoplasm occur (Fig. 1a, b, c). The very detailed studies on D. melanogaster (Wieshaus \& Nüsslein-Volhard, 1986) revealed that nuclei multiply exponentially in the central region of an egg during early cleavage. The majority of dividing nuclei surrounded by protoplasmic islands start their migration outwards to the periplasm, leaving the future yolk nuclei behind.

Stage 2 (3-9 h): The depth of yolk-free periplasm increases at the expense of the central yolk region (YK). There are clear caps of posterior polar cytoplasm resulting from the retraction of cytoplasm from the vitelline membrane $(\mathrm{VM})$ at the poles. The pole buds $(\mathrm{BC})$ divide to produce the pole cells (Fig. 2a, b, c).
Stage $3(9-21 \mathrm{~h})$ : Blastoderm cell layer becomes thick and clearly demarcated from the yolk. The cellular blastoderm (BD) is a characteristic marker of this stage. The gastrulation movements begin (Fig. 3a, b, c).

Stage $4(21-57 \mathrm{~h})$ : Gastrulation stage: about one-fourth of the distance down from the anterior pole is a section of the cephalic furrow (anterior oblique cleft) and the invagination at the posterior pole is part of the posterior midgut furrow (also called the amnio-proctodeal invagination). The cephalic folds gradually disappear and the stomodeal plate (ST) is formed. The gut opening has reached the head region three quarters along the egg length and the cephalic furrow is no longer visible. The germ band (GB) extends to maximum size. Parasegmental furrows (PS) appear (Fig. 4a, b, c).

Stage 5 (57-66 h): Germ band shortens. When the stomodeum (ST) forms the anterior tip of the embryo bends ventrally and an invagination appears and deepens. The anterior midgut anlage moves posteriorly reaching and passing the level of the posterior gut opening at the same time flattening out along the ventral germ band. The head bends dorsally and a gap at the anterior ventral region of the head enlarges (Fig. 5a, b, c).

Stage $6(66-75 \mathrm{~h})$ : The germ band (GB) is completely contracted. Ectodermal parasegmentation becomes clear. 


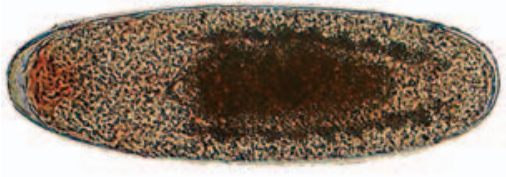

$7 a$

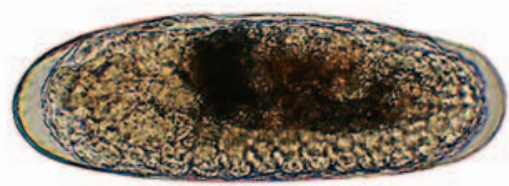

$7 \mathrm{~b}$
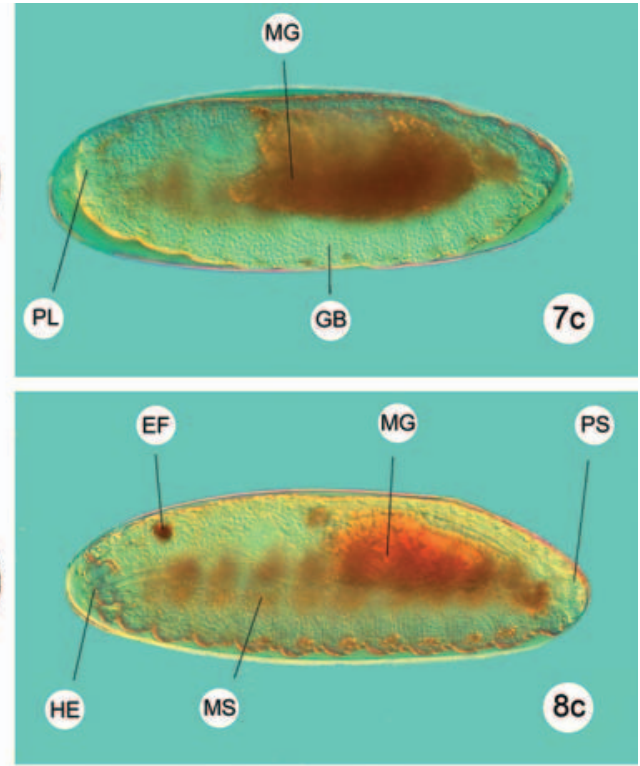

$8 \mathrm{c}$

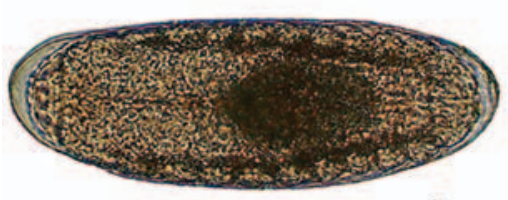

$8 \mathrm{a}$

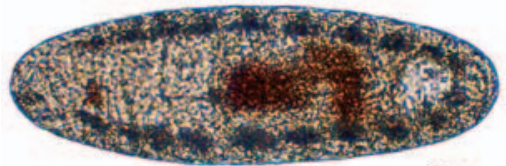

$9 a$

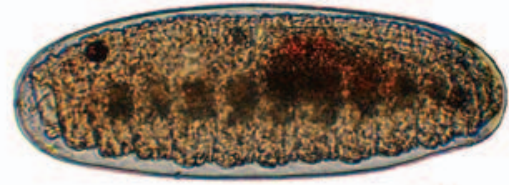

$8 b$

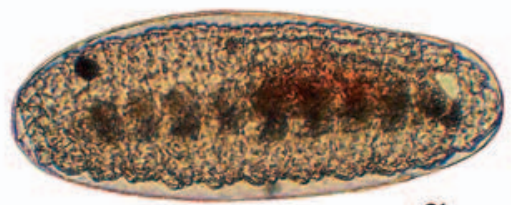

$9 \mathrm{~b}$

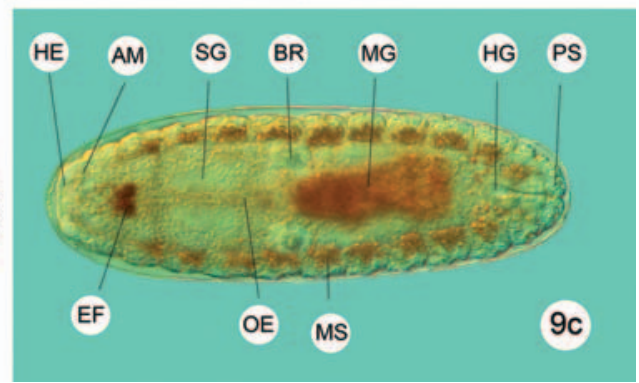

Figs 7-9. Stage 7: Head involution. GB - germ band; PL - procephalic lobe; MG - midgut. Stage 8: Dorsal ridge overgrows tip of clypeolabrum; midgut and dorsal closure. HE - head; EF - eye-fleck; MG - midgut; MS - muscles; PS - posterior spiracles. Stage 9: Muscular movements; white vacuole in the hindgut region. HE - head; AM - Antennal-mandibullary complex; EF - eye-fleck; MS - muscles; SG - salivary glands; OE - oesophagus; BR - brain; MG - mid gut; HG - hind gut; PS - posterior spiracles.

The yolk sac (YK) is initially concave dorsally and changes to a convex shape at the end of this stage. The posterior midgut (MG) opening moves posteriorly and the yolk sac, covered by the amnio-serosa (AS), extends to the dorsal surface of the embryo. The head region is distinct. A ridge forms dorsally at the posterior margin of the head. The clypeo-labrum (CL) and stomodeum (ST) are distinct (Fig. 6a, b, c).

Stage 7 (75-90 h): The germ band (GB) stretches anteriorly and a head portion (PL) involutes into the interior of the embryo and is continuous with the stomodeal opening. Ventral layers become apparent and gradually flatten out along the yolk sac (MG). The hindgut grows anterodorsally. Dorsal closure continues (Fig. 7a, b, c).

Stage 8 (90-117 h): Intersegmental grooves are clear in the mid-dorsal region; dorsal ridge overgrows the tip of clypeo-labrum. Head (HE) involution and dorsal closure of the ectoderm occur. Frontal sac formation begins as the dorsal ridge and moves anteriorly covering the head region. There is a well-marked antennal-mandibullary complex on the head. The eye-fleck (EF) is clearly distinct. In the frontal part of embryo there are salivary glands (SG), oesophagus (OE) and brain (BR). The posterior midgut $(\mathrm{MG})$ broadens dorsally. During this stage dorsal closure of the musculature and gut occurs. The midgut initially assumes an "elliptical shape". Subsequently constrictions divide the midgut (8c) into three regularly spaced subdivisions (Fig. 8a, b, c).

Stage 9 (117-144 h): muscular (MS) movements begin in the gut and are soon apparent in the somatic musculature as well. White coloured spherical hindgut (HG) appears. Posterior spiracles (PS) are distinct (Fig. 9a, b, c).

Stage $10(>144 \mathrm{~h})$ : Newly hatched larva appears after disruption of the chorion as a result of convulsive movement in late embryogenesis (Fig. 10a, b, c).

\section{Comparison with Drosophila}

In contrast to the seventeen stages distinguished in Drosophila embryonic development (Campos-Ortega \& Hartenstein 1985; Wieshaus \& Nüsslein-Volhard, 1986 and Ashburner, 1989), we (to simplify the description) distinguished only ten stages (Table 1). Only five stages are defined by means of distinct markers before the termination of gastrulation (in comparison to the seven stages in Drosophila embryonic development) and only six before completion of germ band shortening (compared to thirteen in Drosophila embryos).

Embryonic development in A. aphidimyza is slower than in D. melanogaster and there are morphological differences between these two species in the late stages of 

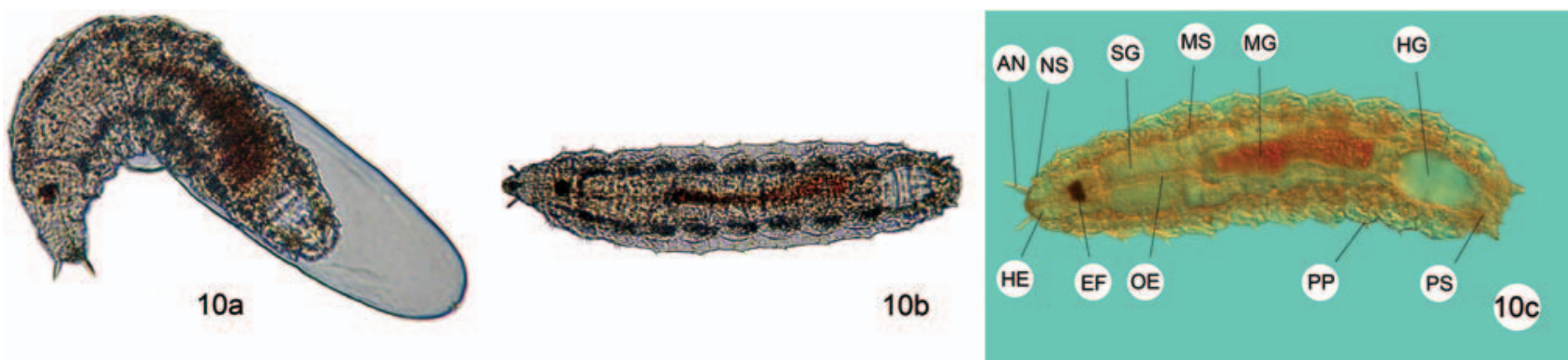

Fig. 10. Hatched larva. AN - antenna; HE - head; NS - neck segment; EF - eye-fleck; MS - muscles; SG - salivary glands; OE oesophagus; $\mathrm{MG}$ - mid gut; HG - hind gut; PP - pleural papilla; PS - posterior spiracles.

embryogenesis (well-differentiated embryo). Among others, the eye fleck, the hindgut form and distinct muscles, characteristic of $8^{\text {th }}$ stage $A$. aphidimyza embryos, are missing in Drosophila.

Length of the gall-midge embryonic development is more than twice that of Drosophila melanogaster - about $102 \mathrm{~h}$ at $17^{\circ} \mathrm{C}$ and $144 \mathrm{~h}$ at $15^{\circ} \mathrm{C}$ (compared to $46 \mathrm{~h}$ for Drosophila reared at $17^{\circ} \mathrm{C}$ ).

\section{DISCUSSION}

There is only one paper on the embryonic development of Cecidomyiid flies (Kahle, 1908). It is a well-illustrated work, but it focuses on parthenogenetic reproduction of larvae of Miastor metraloas Meinert.

The numbering of the embryonic stages and the morphological criteria for their identification depend on the aim of investigators. A total of 17 stages are used in embryological studies of Drosophila (Campos-Ortega \& Hartenstein, 1985; Wieshaus \& Nüsslein-Volhard, 1986; Ashburner, 1989), and only eleven morphological stages in the blowfly, Calliphora erythrocephala (van der Starre-van der Molen, 1972).

Detailed study of embryogenesis makes the selection of the most appropriate developmental stage possible. It is very difficult to evaluate results of experiments on cryoprotection without reference to embryonic development. For example, Miles \& Bale (1995a) tested cryopreservation using glycerol and methanol on a limited number of eggs of $A$. aphidimyza. They had only three groups of 10 eggs, 2 to $17 \mathrm{~h}$ old (probably kept at $22^{\circ} \mathrm{C}$ ). It is obvious, that they used a mixture of early embryonic stages (probably stages 1-3), with high yolk contents. According to Mazur et al. (1992), early embryos are chillsensitive and this was probably the cause of cryopreservation failure in the experiments of Miles \& Bale (1995a). Mathematical modelling (Miles \& Bale 1995b) of the effect of the cooling rate and exposure to low temperatures $\left(0-20^{\circ} \mathrm{C}\right)$ for short periods on egg survival are meaningless if the cryo-treatment is applied to an unsuitable embryonic stage of $A$. aphidimyza eggs.

The papers on cryopreservation of dipteran embryos (mentioned above) include information that indicate the importance of using embryos at a particular stage in their development or exhibit a particular "markers", or give reasons why the latter stages of development are better for treatment than earlier stages. For example - in Lucilia cuprina (Calliphoridae) the best are embryos at the point of dorsal closure (Leopold \& Atkinson, 1999). For the Mediterranean fruit fly (Ceratitis capitata) the optimal stage is after incubation for $27 \mathrm{~h}$ at $29^{\circ} \mathrm{C}$ (Rajamohan et al., 2003). For Drosophila melanogaster it is freshly laid eggs kept for $20 \mathrm{~h}$ at $17.5^{\circ} \mathrm{C}$ (at which time $90 \%$ of embryos are generally at stage 14) (Mazur et al., 1992). A critical evaluation of the published results indicates that, except for the Anopheles mosquito, cryopreservation of the other dipteran embryos is only possible if they can survive permeabilization, there is little yolk left, and the embryo has not formed an impermeable body wall in the form of a cuticle.

The staging system of living embryos of the predatory gall midge $A$. aphidimyza presented here includes ten stages characterized by distinct morphological markers. Stage 6, appears to be the most appropriate for cryopreservation.

ACKNOWLEDGEMENTS. This work was supported by grants No. S5007102 and 522/98/0228 of the Grant Agency of the Czech Republic. The authors are grateful to K. Dusbabová for her technical assistance and F. Sehnal for stylistic revision.

\section{REFERENCES}

AsYaKIN B.P. 1974: Aphidophagous insects and their use in aphid suppression on cucumbers in glasshouses. Ph.D. Thesis, Leningrad Agric. Inst., 211 pp. [in Russian].

Ashburner M. 1989: Drosophila - A Laboratory Handbook. Cold Spring Harbor Laboratory Press, Plainview, NY, pp. 139-298.

Campos-Ortega J.A. \& Hartenstein V. 1985: The Embryonic Development of Drosophila melanogaster. Springer, Berlin, Heidelberg, $227 \mathrm{pp}$.

HavelKa J. 1980: Effect of temperature on the developmental rate of preimaginal stages of Aphidoletes aphidimyza (Diptera, Cecidomyiidae). Entomol. Exp. Appl. 27: 83-90.

Havelka J. 1982: A predatory gall-midge Aphidoletes aphidimyza (Rondani) (Diptera, Cecidomyiidae) - a method of mass laboratory rearing, and use in the biological control of aphids on greenhouse plants. Proc. IOBC East Palaearctic Regional Section: Methods of Integrated Pest Management. Poznań, Poland, pp. 89-121 [in Russian].

HAVELKA J. 1996: Storage of entomophagous insects: methods and use (a review). Proc. Symp. IOBC EPRS \& WPRS: Ecological Problems of Plant Protection and Contemporary Agriculture. Bratislava, pp. 55-57.

HavelKa J. \& ZemeK R. 1988: Intraspecific variability of aphidophagous gall midge Aphidoletes aphidimyza (Rondani) 
(Dipt., Cecidomyiidae) and its importance for biological control of aphids. J. Appl. Entomol. 105: 280-288.

HAVELKa J. \& ZeMeK R. 1999: Life table parameters and oviposition dynamics of various populations of the predacious gall midge Aphidoletes aphidimyza. Entomol. Exp. Appl. 91: $481-484$.

Heacox A.E., Leopold R.A. \& Brammer J.D. 1985: Survival of house fly embryos cooled in the presence of dimethyl sulfoxide. Cryo-Letters 6: 305.

Kahle W. 1908: Die Paedogenesis der Cecidomyiden. Zoologica (Stuttgart) 21: 1-80.

KošŤÁL V. \& HavelKa J. 2001: Low temperature storage of larvae and synchronization of adult emergence in the predatory midge Aphidoletes aphidimyza. Cryobiology 42: $112-120$

Kulp D., Fortmann M., Hommes M. \& Plate H.P. 1989: Die räuberische Gallmücke Aphidoletes aphidimyza (Rondani) (Diptera: Cecidomyiidae) - Ein bedeutender Blattlausprädator - Nachschlagewerk zur Systematik, Verbreitung, Biologie, Zucht und Anwendung. Mitt. Biol. Bund. Land Forstw. (Berlin) 250: 1-126.

LEOPOLD R.A. 1991: Cryopreservation of insect germplasm: Cells, tissues and organisms. In Lee R.E. \& Denlinger D.L. (eds): Insects at Low Temperature. Chapman \& Hall, New York, pp. 379-407.

Leopold R.A. \& AtKinson P. 1999: Cryopreservation of sheep blow fly embryos, Lucilia cuprina (Diptera: Calliphoridae). Cryo-Letters 20: 37-44.

Leopold R.A., Wang W.B., Berkebile D.R. \& Freeman T.P. 2001: Cryopreservation of embryos of the New World screwworm, Cochliomyia hominivorax (Diptera: Calliphoridae). Ann. Entomol. Soc. Am. 94: 695.

LIU X.H. \& MAzUR P. 2003: Effects of sugars on the kinetics of drying and on the survival of partially dehydrated larvae of Anopheles mosquitos. J. Insect Physiol. 49: 685-695.

Liu X. H., Mazur P., Gamliel E., Cole K.W. \& Laughinghouse A. 2001: Effects of beserazide, dechorionation time in hypochlorite, and alkane treatment on the permeability of Anopheles gambiae eggs to water and solutes. Cryobiology 43: $341-342$.

Liu X.H., PAN H. \& Mazur P. 2003: Permeation and toxicity of ethylene glycol and methanol in larvae of Anopheles gambiae. J. Exp. Biol. 206: 2221.

MarkKula M. \& Tittanen K. 1977: Use of the predatory midge Aphidoletes aphidimyza (Rond.) (Diptera, Cecidomyiidae) against aphids in glasshouse cultures. Proc. Symp. XV. Int. Congr. Entomol. Wash. D.C. USDA AS ARS-NE 85: 41-44.

Mazur P. \& Cole K.W. 1992: Cryobiological preservation of Drosophila embryos. Science 258: 1932-1935.
Mazur P., Schneider U. \& Mahowald A.P. 1992: Characteristics and kinetics of subzero chilling injury in Drosophila embryos. Cryobiology 29: 39-68.

Mazur P., Cole K.W., Schreuders P.D. \& Mahowald A.P. 1993: Contributions of cooling and warming rate and developmental stage to the survival of Drosophila embryos cooled to $-205^{\circ}$ C. Cryobiology 30: 45 .

Miles J.E. \& BALE J.S. 1995a: Steps towards the cryopreservation of the biological control agent Aphidoletes aphidimyza Rond. (Diptera, Cecidomyiidae). Cryo-Letters 16: 329-338.

Miles J.E. \& BALE J.S. 1995b: Analysis of chilling injury in the biological control agent Aphidoletes aphidimyza. Cryobiology 32: 436-443.

Myers S.P., Lynch D.V., Knipple D.C., Leibo S.P. \& Steponkus P. 1988: Low-temperature sensitivity of Drosophila melanogaster embryos. Cryobiology 25: 544-545.

NunAmaker R.A. \& Lockwood J.A. 2001: Cryopreservation of embryos of Culicoides sonorensis (Diptera: Ceratopogonidae). J. Med. Entomol. 38: 55-58.

Poulson D.F. 1950: Histogenesis, organogenesis, and differentiation in the embryo of Drosophila melanogaster Meigen. In Demerec M. (ed.): Biology of Drosophila. John Wiley \& Sons, New York, pp. 168-274.

Rajamohan A., Leopold R.A., Wang W.B., Harris M., McCombs S.D., Peabody N.C. \& Fisher K. 2003: Cryopreservation of Mediterranean fruit fly embryos. Cryo-Letters 24: $125-132$.

SonNEnBLICK B.P. 1950: The early embryology of Drosophila melanogaster. In Demerec M. (ed.): Biology of Drosophila. John Wiley \& Sons, New York, pp. 62-167.

Steponkus P.L., Myers S.P., Lynch D.V., Gardner L., Bronhteyn V., Leibo S.P., Rall W.F., Pitt R.E., Lin T.T. \& MacinTYRe R.J. 1990: Cryopreservation of Drosophila melanogaster embryos. Nature 345: 170-172.

Valencia M.D.P., Miller L.H. \& Mazur P. 1996a: Permeability of intact and dechorionated eggs of the Anopheles mosquito to water vapour and liquid water: A comparison with Drosophila. Cryobiology 33: 142-148.

Valencia M.D.P., Miller L.H. \& Mazur P. 1996b: Permeabilization of eggs of the malaria mosquito Anopheles gambiae. Cryobiology 33: 149-162.

Van der Starre-Van der Molen L.G. 1972: Embryology of Calliphora erythrocephala Meigen. 1. Morphology. Neth. J. Zool. 22: 119-182.

Wang W.B., Leopold R.A., Nelson D.R. \& Freeman T.P. 2000: Cryopreservation of Musca domestica (Diptera: Muscidae) embryos. Cryobiology 41: 153-166.

Wieshaus E. \& Nüsslein-Volhard C. 1986: Looking at embryos. In Roberts D.B. (ed.): Drosophila - A Practical Approach. Oxford Univ. Press, New York, pp. 199-227.

Received November 15, 2005; revised and accepted August 14, 2006 